\title{
TU/e emonowne

\section{Corona charging and optical second-harmonic generation studies of the field-effect passivation of c-Si by Al2O3 films}

\section{Citation for published version (APA):}

Mandoc, M. M., Adams, M. L. C., Dingemans, G., Terlinden, N. M., \& Sanden, van de, M. C. M. (2010). Corona charging and optical second-harmonic generation studies of the field-effect passivation of c-Si by Al2O3 films. In Proceedings of the 35th IEEE Photovoltaic Specialist Conference (PVSC), 20- 25 June, 2010, Honolulu, Hawaii https://doi.org/10.1109/PVSC.2010.5616794

DOI:

10.1109/PVSC.2010.5616794

Document status and date:

Published: 01/01/2010

\section{Document Version:}

Publisher's PDF, also known as Version of Record (includes final page, issue and volume numbers)

\section{Please check the document version of this publication:}

- A submitted manuscript is the version of the article upon submission and before peer-review. There can be important differences between the submitted version and the official published version of record. People interested in the research are advised to contact the author for the final version of the publication, or visit the $\mathrm{DOI}$ to the publisher's website.

- The final author version and the galley proof are versions of the publication after peer review.

- The final published version features the final layout of the paper including the volume, issue and page numbers.

Link to publication

\section{General rights}

Copyright and moral rights for the publications made accessible in the public portal are retained by the authors and/or other copyright owners and it is a condition of accessing publications that users recognise and abide by the legal requirements associated with these rights.

- Users may download and print one copy of any publication from the public portal for the purpose of private study or research.

- You may not further distribute the material or use it for any profit-making activity or commercial gain

- You may freely distribute the URL identifying the publication in the public portal.

If the publication is distributed under the terms of Article 25fa of the Dutch Copyright Act, indicated by the "Taverne" license above, please follow below link for the End User Agreement:

www.tue.nl/taverne

Take down policy

If you believe that this document breaches copyright please contact us at:

openaccess@tue.nl

providing details and we will investigate your claim. 


\title{
CORONA CHARGING AND OPTICAL SECOND-HARMONIC GENERATION STUDIES OF THE FIELD-EFFECT PASSIVATION OF $c$-SI BY $\mathrm{Al}_{2} \mathrm{O}_{3}$ FILMS
}

\author{
M. M. Mandoc, M. L. C. Adams, G. Dingemans, N. M. Terlinden, M. C. M. van de Sanden, \\ W. M. M. Kessels
}

Department of Applied Physics, Eindhoven University of Technology, P.O. Box 513, $5600 \mathrm{MB}$ Eindhoven, The Netherlands

\begin{abstract}
Aluminum oxide films $\left(\mathrm{Al}_{2} \mathrm{O}_{3}\right)$ synthesized by atomic layer deposition (ALD) provide an excellent level of surface passivation of $n-, p$-, and heavily doped $p$-type crystalline silicon $(c-\mathrm{Si})$. It has been shown that a negative fixed charge density in the order of $10^{12}-10^{13} \mathrm{~cm}^{-2}$ can be present at the interface of $\mathrm{Al}_{2} \mathrm{O}_{3}$ with $c$-Si, inducing a high level of field-effect passivation. In this contribution we report on results obtained by two complementary, contactless techniques to investigate the field-effect passivation for the $\mathrm{Al}_{2} \mathrm{O}_{3} / c$-Si case: optical secondharmonic generation ( $\mathrm{SHG}$ ) and corona charging. From an extensive data set on $\mathrm{Al}_{2} \mathrm{O}_{3}$ thin films, we demonstrate that the combination of SHG and corona charging offers the advantage of probing the presence of fixed charges at the interface non-intrusively (SHG) and of extracting the fixed charge density quantitatively (corona). These two techniques are therefore powerful tools for investigating the mechanisms responsible for the passivation properties of thin films.
\end{abstract}

\section{INTRODUCTION}

The decrease in $c$-Si wafer thickness for solar cells means less material consumption and therefore lower costs. An important aspect in reducing the wafer thickness is that recombination at surfaces and interfaces plays a bigger role, affecting the device performance. Also, in order to achieve better solar cell performance, internal losses such as recombination at surfaces and interfaces need to be minimized. Therefore, surface passivation schemes must be employed for high-efficiency solar cells. The passivation can be of chemical nature, such as reducing the defect density at the interface, it can be field-induced, given by the presence of fixed charges at the interface, or a combination of both.

One of the most promising materials for surface passivation of $c$-Si is $\mathrm{Al}_{2} \mathrm{O}_{3}[1,2] . \mathrm{Al}_{2} \mathrm{O}_{3}$ films have lead to excellent results on $n-, p$-, and heavily doped $p$-type crystalline silicon (c-Si) using ALD [2, 3] and PECVD [4] as deposition method. Sputtering has also been recently employed [5]. Through its cyclic nature, the ALD process is able to control the film deposition and material properties down to atomic level, yielding films with high uniformity and conformality. Depending on the reactant used, the process can be plasma-assisted, in which the reactant is an oxygen $\left(\mathrm{O}_{2}\right)$ plasma, or alternatively water or ozone, in a so-called thermal ALD process. Though the water-based thermal ALD process is more well established, plasma-assisted ALD offers advantages such as a shorter deposition time (shorter purge steps), higher growth-per-cycle, and lower deposition temperatures [6]. It has been shown that an annealing step is required to fully activate the high surface passivation of both plasma and thermal ALD $\mathrm{Al}_{2} \mathrm{O}_{3}$ films [7, 8]. In as-deposited state, thermal ALD films show better surface passivation than plasma-assisted ones. However, after annealing, the films passivation quality becomes comparable [8]. For plasmaassisted films, deposited by ALD and PECVD, it has been shown that field-effect passivation is present, due to fixed negative charges at the $c-\mathrm{Si} / \mathrm{Al}_{2} \mathrm{O}_{3}$ interface $[1,8]$. Therefore, investigation of field-effect properties is an important step in understanding the different passivation mechanisms of the films. For this purpose, diagnostics tools sensitive to the presence of fixed charges are needed. Among others, important aspects of such techniques are the sensitivity to surfaces and interfaces, the ability to quantify the charge, and to preserve sample integrity. In this work we report on results obtained using two complementary, contactless techniques to investigate the field-effect passivation for the $\mathrm{Al}_{2} \mathrm{O}_{3} / c$-Si case: optical second-harmonic generation (SHG) and corona charging. We show that by combining these two techniques, we can obtain a qualitative, as well as quantitative evaluation of fixed charges present at the interface of $\mathrm{Al}_{2} \mathrm{O}_{3}$ with $c$-Si.

\section{OPTICAL SECOND-HARMONIC GENERATION}

As an all-optical, contactless and non-destructive technique, SHG has been proven to be highly sensitive to surfaces and interfaces, and it has been widely used in $c$ Si surface science. Its sensitivity comes from the fact that it is essentially symmetry forbidden in the bulk of centrosymmetric media such as $c$-Si. The generation of second-harmonic radiation is possible at the surfaces and interfaces, where the symmetry of the solid is broken. SHG is sensitive to dangling bonds, interface states, and the presence of internal, or externally applied electric fields $[10,11]$

SHG is a non-linear optical process, due to the interaction of high intensity light with a medium. When low intensity light interacts with a material, it produces a polarization field which oscillates with same frequency as the incoming 
(a)

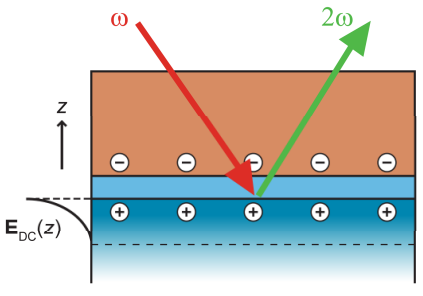

(b)

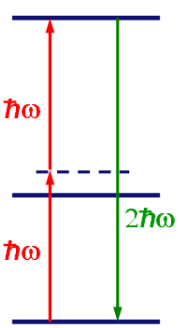

Figure 1. (a) Principle of the optical SHG technique: high intensity laser radiation of frequency $\omega$ generates radiation with the frequency $2 \omega$ at the interface. The SHG response is sensitive to the electric field present at the interface. (b) Schematic representation of the case where the SHG photon energy coincides with a real electronic transition in the material, leading to resonant enhancement of the signal. This case describes SHG generation for our particular system of $c-\mathrm{Si} / \mathrm{Al}_{2} \mathrm{O}_{3}$.

electromagnetic field. However, when high intensity light is used, such as femtosecond laser pulses, non-linear processes can take place. Second-harmonic generation means that there is a contribution to the polarization field in the medium at double the frequency of the fundamental radiation. In this case, within the electric dipole approximation (assuming spatially homogeneous fields) the polarization can be described by [10]:

$$
\mathbf{P}=\varepsilon_{0} \stackrel{\leftrightarrow}{\chi}^{(1)} \cdot \mathbf{E}+\varepsilon_{0} \overleftrightarrow{\chi}^{(2)}: \mathbf{E} \mathbf{E}+\ldots
$$

where $\overleftrightarrow{\chi}$ is the electric susceptibility, $\mathbf{E}$ the electric field at a frequency $\omega$, and $\varepsilon_{0}$ the permittivity of free space. The second-harmonic contribution at the frequency $2 \omega$ is given by the second term in Equation (1).

Microscopically, SHG can be regarded as the conversion of two photons with energy $\hbar \omega$ into one photon with double the energy of the fundamental radiation ( $2 \hbar \omega)$. When the photon energy of the fundamental or the SHG radiation coincides with a real electronic transition in the medium, the SHG response is resonantly enhanced. The presence of DC electric fields in the medium gives rise to electric-field-induced second harmonic, or EFISH, which is described by the second and third term of the polarization component at $2 \omega$ :

$$
\begin{aligned}
\mathbf{P}(2 \omega)= & \varepsilon_{0} \overleftrightarrow{\chi}^{(2)}(2 \omega): \mathbf{E}(\omega) \mathbf{E}(\omega)+\varepsilon_{0} \overleftrightarrow{\chi}_{s}^{(3)}(2 \omega): \mathbf{E}(\omega) \mathbf{E}(\omega) \\
& \mathbf{E}_{\mathrm{dc}(\text { surf })}+\varepsilon_{0} \overleftrightarrow{\chi}_{B}^{(3)}(2 \omega): \mathbf{E}(\omega) \mathbf{E}(\omega) \mathbf{E}_{\mathrm{dc}(\text { bulk })}
\end{aligned}
$$

In Equation (2) the second term describes the EFISH surface contribution and the third term the bulk contribution. In fact, $\overleftrightarrow{\chi}_{B}^{(3)}$ and $\overleftrightarrow{\chi}_{S}^{(3)}$ are tensors of rank four. With the dc electric field perpendicular to the surface, the electric susceptibility tensors of EFISH components have

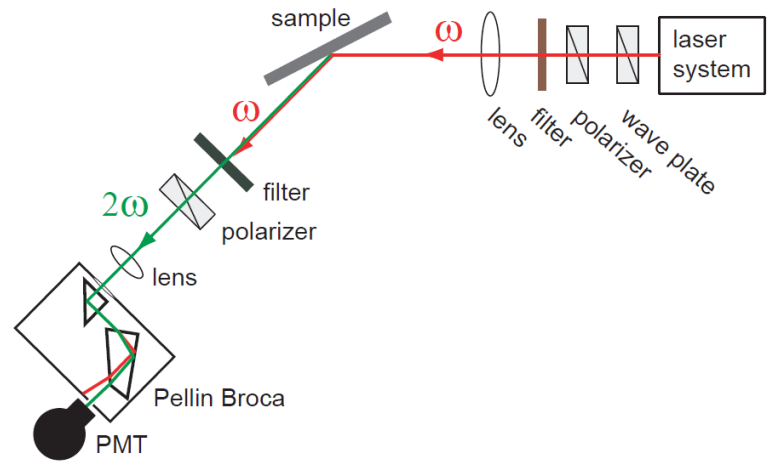

Figure 2. Optical setup used in this work to generate and detect $S H G$ radiation.

symmetry properties identical to the dipole contribution represented by the first term of Equation (2).

DC electric fields can arise due to the presence of fixed charges, or an applied external bias. The high sensitivity of SHG technique to a wide range of material properties (dangling bonds, surface states, electric fields) means that the interpretation of SHG response plays a major role in disentangling the possible contributions to the overall SHG signal. For thin-films on $c$-Si, the different contributions to the SHG spectra have been separated using a model in which the SHG intensity is given by a coherent superposition of critical point (CP)-like resonances in $c-\mathrm{Si}$ [10-12].

The optical setup used for SHG measurements is schematically represented in Figure 2 [10]. The laser light is generated by a Ti:sapphire oscillator, with a tunable wavelength in the range $710-930 \mathrm{~nm}$ (1.33-1.75 photon energy range). The Ti:sapphire oscillator operates at a repetition rate of $80 \mathrm{MHz}$, with a pulse duration of $90 \mathrm{fs}$. The desired polarization direction of the fundamental beam and the power is selected using a polarizer and a variable wave plate. Any incoming radiation to the sample at SHG wavelength is suppressed with a color filter. The SHG radiation is generated in reflection at the sample, and its polarization direction is selected using a polarizer. The fundamental radiation reflected at the sample is suppressed by two color filters. The remaining beam goes through a Pellin-Broca dispersing prism, where the fundamental and SHG radiation are spatially separated. In this way, only SHG radiation reaches the detector, which consists of a photomultiplier tube connected to singlephoton counting electronics. All measurements have been performed for $p$-polarized fundamental and secondharmonic radiation.

\section{CORONA CHARGING}

Being a contactless technique as well, corona charging can be a useful tool to investigate the presence of field-effect passivation [13, 14]. The effect of fixed 
charges in the material is counteracted by applying corona charges on the sample surface. The change in lifetime of the sample, which is indicative of the passivation properties, is monitored. A more convenient way of characterizing the level of passivation at the interface is by calculating the effective surface recombination velocity [7]. For an interface with negative fixed charge, such as $\mathrm{Al}_{2} \mathrm{O}_{3} / c$-Si, electrons are repelled from the interface and as a result, the surface recombination is reduced. By applying positive corona charges on the sample surface, the effect of the fixed negative charges is counteracted, and electrons in $c$-Si are less shielded from the interface. As a result, the surface recombination increases. The surface recombination reaches a maximum at the point where the field-effect passivation is in essence nullified, the remaining passivation being of chemical nature. Corona charging of the sample beyond this point will result in a decrease in the surface recombination velocity, as the carriers of opposite sign in $\mathrm{c}$-Si are accumulated at the interface. The applied corona charge necessary to compensate the field-effect passivation is a measure of the amount of fixed charge present in the film, and can be determined using a Kelvin probe $[13,14]$. Therefore, with corona charging, the presence of field-effect passivation and the amount of fixed charge can be determined. Compared to the use of metal gates, corona charging has the advantage that in case of oxide breakdown, the current will be confined to the breakdown area, due to the low mobility of corona charges along the sample surface. The deposited charges can be removed, if desired, by rinsing the sample in water or alcohol [13].

The corona setup used in this work is shown schematically in Figure 3a. To a tungsten needle, a high voltage $(9 \mathrm{kV})$ is applied. The high strength electric field generated at the tip of the needle ionizes the surrounding air molecules. The ionized molecules follow the field lines, and are deposited on the sample. As the mean free path is very short at atmospheric pressure, ionized molecules reach the sample having negligible kinetic energy, therefore without damaging the sample surface [14]. To improve charge deposition uniformity, a metallic mesh is used, placed close to the sample, on which a low voltage is applied. The negative species created are mainly $\mathrm{CO}_{3}{ }^{-}$ ions, while for positive charging these are mainly $\mathrm{H}_{3} \mathrm{O}^{+}$ (hydrated protons) [13].

The charge deposited on the sample surface can be detected with a Kelvin probe (Figure 3b). The Kelvin probe acts as a vibrating capacitor, formed between the probe electrode and the sample. By electromechanically vibrating the probe electrode, a capacitive modulation is induced between the probe and the sample. If the electrode and the sample have dissimilar surface voltages (surface charge), an AC current will flow from/to the probe. The null-method used to measure the surface charge by the Kelvin probe is to nullify this current, and therefore, the probe is driven to the same voltage as on the sample surface. From the measured voltage, corona charge on the surface can be derived from [14]:

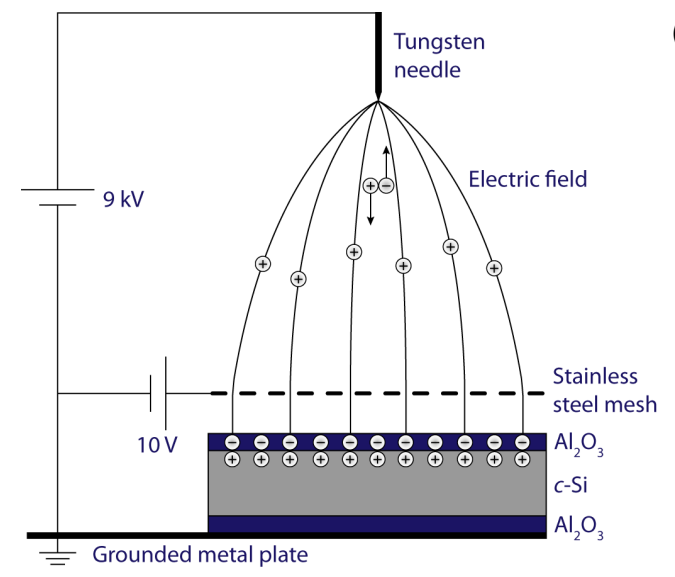

(a)

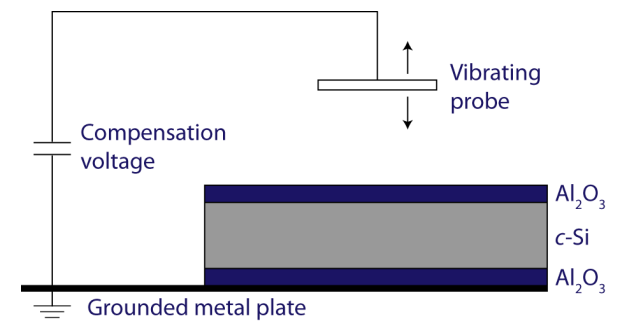

(b)

Figure 3. Schematic representation of the corona charging setup (a), and of the Kelvin probe (b) used in this work.

$V_{S}=\frac{q Q_{\text {corona }}}{C_{d}}$

with $V_{S}$ the surface voltage, $q$ the electron charge and $C_{d}$ the capacitance of the dielectric film.

For the case of $c-\mathrm{Si} / \mathrm{Al}_{2} \mathrm{O}_{3}$ system, any contribution to the surface voltage coming from the buried interface is below $1 \mathrm{~V}$, and it is not taken into account in the calculation of surface charge (see also Ref. 13). We note that the overall error inherent to the measurements is such that this contribution from the buried interface is less significant.

\section{RESULTS}

It has been shown that an annealing step is required to fully activate the passivation properties for both plasma-assisted and thermal ALD films [7, 8]. In Figure 4, deconvoluted SHG spectra are shown for plasma and thermal ALD $\mathrm{Al}_{2} \mathrm{O}_{3}$ films on $c$-Si, for the as-deposited and annealed case. The resonance at the SHG photon energy of $3.4 \mathrm{eV}$ corresponds to $\mathrm{Si}$ interband transition at the $E_{0}{ }^{\prime} / E_{1}$ critical point $(C P)[12,15]$. There are however 
Thermal ALD

(a)
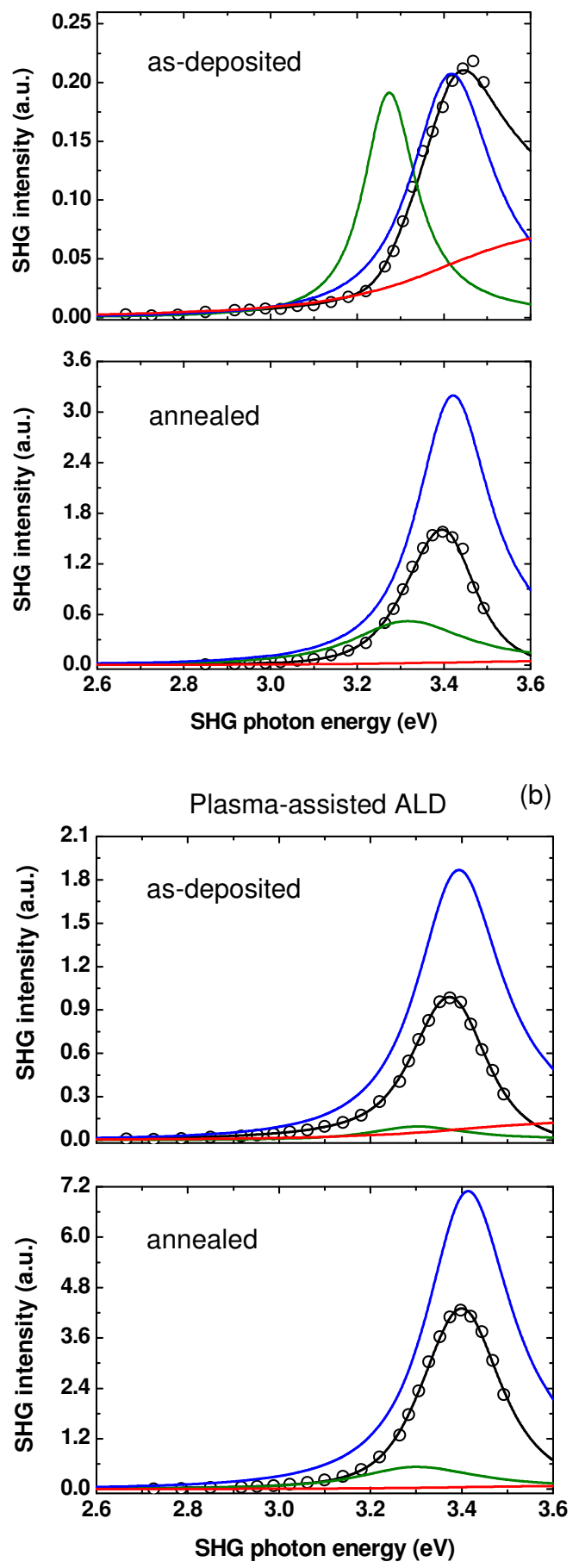

Figure 4. SHG spectra measured (symbols) for (a) thermal and (b) plasma-assisted $\mathrm{ALD} \mathrm{Al}_{2} \mathrm{O}_{3}$ films, both for the as-deposited and annealed case. The black lines are results from simulations that take into account the multiple SHG contributions: EFISH (blue lines), Si-Si bonds at the interface (green lines), and $\mathrm{Si}$ bonds strained due to the presence of $\mathrm{SiO}_{x}$ (red lines). multiple contributions to this resonance: EFISH coming from the silicon space-charge-region $(\sim 3.4 \mathrm{eV})$, a contribution from Si-Si bonds at the interface $(\sim 3.3 \mathrm{eV})$, and also a contribution from Si bonds which are distorted due to the presence of silicon oxide $\left(\mathrm{SiO}_{\mathrm{x}}\right)$ at the interface $(\sim 3.6 \mathrm{eV})$ [15]. It can be seen that there is a significant increase in the EFISH contribution after anneal, for both plasma and thermal ALD films, which indicates that the amount of fixed charges increases upon annealing. Therefore, a higher field-effect passivation is achieved after annealing for both thermal and plasma-assisted ALD $\mathrm{Al}_{2} \mathrm{O}_{3}$ films. We note that the low lifetimes of as-deposited samples [8] would make corona charging quite difficult for the as-deposited case. With a low starting value, it can be challenging to measure the change in the lifetime of the sample, when charging. In that sense, the SHG technique has the advantage of being able to probe the presence of charge regardless of sample lifetime, and its high sensitivity makes it applicable to relatively low amounts of charge.

From the graphs in Figure 4, we see that plasma-assisted samples contain a higher amount of fixed charges as the thermal ALD samples, for both the as-deposited and annealed case. Therefore, the lower lifetimes obtained for as-deposited plasma-assisted films [8] can be attributed to a lower level of chemical passivation.

Using corona charging, an indication of the level of chemical passivation can be obtained, together with the amount of fixed charge, which makes this technique complementary to the qualitative SHG measurements. The amount of fixed charges is given by the amount of corona charges necessary to compensate the field-effect. At this compensation point, the remaining passivation is of chemical nature. The surface recombination velocity measured at this compensation point gives an indication of the level of chemical passivation in the sample. Therefore, corona charging offers not only the possibility to measure the presence of field-effect passivation, but also to obtain an idea about the chemical passivation.

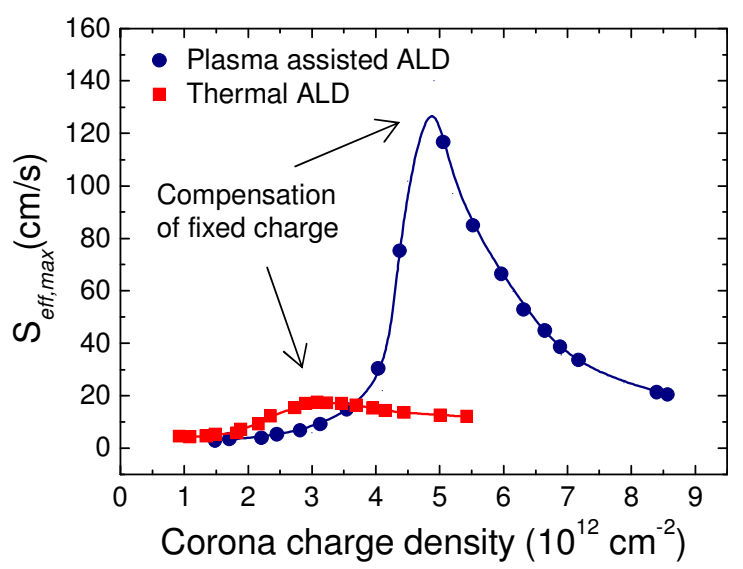

Figure 5. Effective surface recombination velocity as a function of applied corona charge density for $\mathrm{Al}_{2} \mathrm{O}_{3}$ films deposited by plasma-assisted and thermal ALD. The 
maximum values of $S_{\text {effmax }}$ correspond to the compensation of the fixed charges by the deposited corona charges and, therefore, are a measure of the $\mathrm{Al}_{2} \mathrm{O}_{3}$ fixed charge density.

In Figure 5, corona charging results are shown for plasmaassisted and thermal ALD films, after annealing. It can be seen that corona charging confirms the SHG results. The plasma-assisted ALD films contain a higher amount of negative charge $\left(\sim 5 \times 10^{12} \mathrm{~cm}^{-2}\right)$ than thermal ALD films $(\sim$ $3 \times 10^{12} \mathrm{~cm}^{-2}$ ).

From the surface recombination velocities obtained at the compensation point, it can be seen that the level of chemical passivation is lower for plasma ALD $\mathrm{Al}_{2} \mathrm{O}_{3}$ (higher SRV) than for thermal ALD $\mathrm{Al}_{2} \mathrm{O}_{3}$. These results, obtained with SHG and corona charging, are in agreement with results from $\mathrm{CV}$ measurements where the defect density and the amount of fixed charges have also been measured [16]. Therefore, it can be seen that the same very good passivation can be achieved for different contributions of chemical and field-effect passivation induced by the films.

\section{CONCLUSIONS}

Through measurements on $c-\mathrm{Si} / \mathrm{Al}_{2} \mathrm{O}_{3}$, we have shown that optical SHG and corona charging are two noncontacting, complementary techniques, which can be used as a powerful tool to characterize the field-effect passivation provided by thin-films on $c$-Si. By combining the high sensitivity of SHG to interface charge, independent of the sample lifetime, with the possibility to extract the actual amount of charge from corona measurements, we have investigated the presence of field-effect passivation for plasma-assisted and thermal ALD $\mathrm{Al}_{2} \mathrm{O}_{3}$ films. We have shown the influence of annealing on the field-effect passivation properties of the films, and compared the level of chemical passivation caused by the films. It can be concluded that the very low surface recombination velocity provided by $\mathrm{ALD} \mathrm{Al}_{2} \mathrm{O}_{3}$ films on $c$-Si is a combination of field-effect passivation, which is more pronounced in plasma-assisted films, and of chemical passivation, which is better achieved for thermal ALD films.

\section{ACKNOWLEDGMENTS}

This work was supported by the German Ministry for the Environment, Nature Conservation and Nuclear Safety (BMU) under contract no. 0325150 ("ALADIN").

\section{REFERENCES}

[1] G. Agostinelli, A. Delabie, P. Vitanov, Z. Alexieva, H. F. W. Dekkers, S. De Wolf, and G. Beaucarne, Solar Energy Materials \& Solar Cells 90, 3438-3443 (2006).
[2] B. Hoex, S. B. S. Heil, E. Langereis, M. C. M. van de Sanden, and W. M. M. Kessels, Appl. Phys. Lett. 89, 042112 (2006).

[3] J. Benick, B. Hoex, M. C. M. van de Sanden, W. M. M. Kessels, O. Schultz, and S. Glunz, Appl. Phys. Lett. 92, 253504 (2008).

[4] G. Dingemans, M. C. M. van de Sanden, and W. M. M. Kessels, Electrochem. Solid-State Lett. 13, 76 (2010).

[5] T.-T. Li, A. Cuevas, Phys. Stat. Sol. - RRL 3, 160-162 (2009).

[6] J. L. van Hemmen, S. B. S. Heil, J. H. Klootwijk, F. Roozeboom, C. J. Hodson, M. C. M. van de Sanden, and W. M. M. Kessels, J. Electrochem. Soc. 154, G165 (2007).

[7] B. Hoex, J. Schmidt, P. Pohl, M. C. M. van de Sanden, and W. M. M. Kessels, J. Appl. Phys. 104, 044903 (2008).

[8] G. Dingemans, R. Seguin, P. Engelhart, M. C. M. van de Sanden, and W. M. M. Kessels, Phys. Stat. Sol. RRL 4, 10-12 (2010).

[9] B. Hoex, J. J. H. Gielis, M. C. M. van de Sanden, and W. M. M. Kessels, J. Appl. Phys. 104, 113703 (2008).

[10] J. J. H. Gielis, Ph.D. thesis, Eindhoven University of Technology, 2008.

[11] J. J. H. Gielis, P. M. Gevers, I. M. P. Aarts, M. C. M. van de Sanden, and W. M. M. Kessels, J. Vac. Sci.

Technol. A 26, 2008, 1519 (2008).

[12] N. M. Terlinden, G. Dingemans, M. C. M van de Sanden, and W. M. M. Kessels, Appl. Phys. Lett. 96, 112101 (2010).

[13] S. W. Glunz, D. Biro, S. Rein, and W. Warta, J. Appl. Phys. 86, 683 (1999).

[14] S. Dauwe, Ph.D. thesis, Hannover University, 2004.

[15] ] J. J. H. Gielis, B. Hoex, M. C. M. van de Sanden, and W. M. M. Kessels, J. Appl. Phys. 104, 073701 (2008).

[16] G. Dingemans et al., Proceedings of the $35^{\text {th }}$ IEEE Photovoltaic Specialist Conference (2010), submitted. 